\title{
HOT for Transit? Transit's Experience of High-Occupancy Toll Lanes
}

\author{
Gregory L. Newmark \\ Center for Neighborhood Technology
}

\begin{abstract}
As more and more regions seek to implement high-occupancy toll or HOT lanes, more and more transit agencies seek knowledge to take advantage of this new infrastructure opportunity. Unfortunately, as is often the case with the rapid diffusion of a new technology, little information is available to guide policy. This research addresses the need for knowledge on the integration of transit with HOT lanes. It first identifies the salient elements of HOT lanes for transit agencies and then systematically compares these features across all 12 HOT lane facilities operating in the United States at the start of 2012. This paper combines a review of the limited literature on HOT lane/transit integration with detailed data collection from functioning projects. The text aims at a general comparison; however, the tables offer an additional degree of detail to facilitate further exploration.
\end{abstract}

\section{Introduction}

Cities in the United States have begun to vary roadway tolls to manage traffic congestion, particularly via the politically-acceptable high-occupancy toll or HOT lane (Fielding and Klein 1993). HOT lanes allow motorists who do not want to face possible freeway congestion to purchase access to a parallel and uncongested tollway. Vehicles that meet an occupancy threshold may access HOT lanes at no cost. ${ }^{1}$ By 2012, 12 such facilities were in operation.

While HOT lanes are promoted as a new option for drivers, they also represent a new option for transit (Fielding 1995). As more and more regions seek to implement HOT lanes, more and more transit agencies seek knowledge to take advantage of this burgeoning infrastructure. Unfortunately, as is often the case with the rapid diffusion of a new technology, there is little information available. The most extensive treatment considers

${ }^{1}$ Orange County's SR-91 is the sole exception to this rule. That HOT lane charges eastbound high-occupancy vehicles half tolls during the afternoon peak. It should be noted that most HOT lanes also allow free access to select sets of vehicle types, such as motorcycles and certain alternatively-fueled vehicles. 
only a quarter of current facilities (Turnbull 2008). Given concerns that transit agencies are not optimizing the opportunity afforded by such congestion pricing (Hardy 2009), there is a need to comprehensively examine and assess the integration of transit with HOT lanes in the United States. This research is a response to that need.

This work identifies the salient elements of HOT lanes for transit and then systematically compares these across all 12 facilities operating at the start of 2012. This research combines a review of the limited literature with detailed data collection from each HOT lane. The text aims at a general comparison; however, the tables offer an additional degree of specificity to facilitate further exploration.

This article contains three sections. The first focuses on the HOT lane itself and how facility origin and configuration can affect transit. The second section describes current transit integration with HOT lanes to provide a cross-sectional look at bus service levels, park-and-ride provision, and transit ridership. The third section explores HOT lane revenue generation and the use of those revenues to fund bus service.

\section{HOT Lanes in the United States}

Figure 1 shows the locations of the 12 HOT lanes in the United States, all of which, with the sole exception of the 2 facilities in Minneapolis, are in the faster-growing South and West. These lanes serve major roadways experiencing sufficient congestion to warrant an express service. Nine are on Interstate highways, two are on state highways, and one is on a U.S. highway.

FIGURE 1.

HOT lanes in the United States

(January 2012)

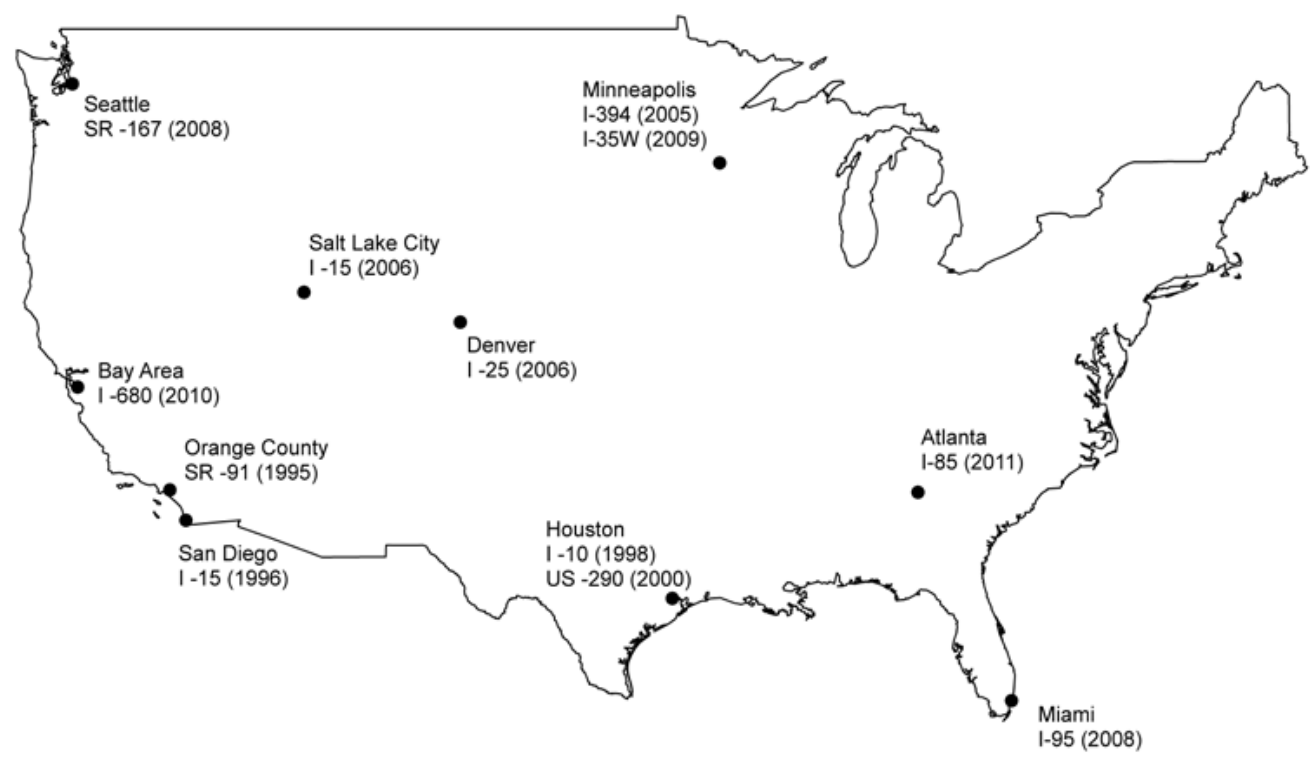

\section{Origin}

Table 1 orders these lanes by their opening dates to show that all HOT lanes have been built since 1995 and two-thirds since 2005. 


\section{TABLE 1.}

HOT Lanes in the United States (January 2012)

\begin{tabular}{|c|c|c|c|c|c|c|c|c|}
\hline Region & Name & Corridor & Opened $^{a}$ & Origin & Miles & Lanes & Reversible & $\begin{array}{c}\text { Separation } \\
\text { Method }\end{array}$ \\
\hline $\begin{array}{l}\text { Orange } \\
\text { County }\end{array}$ & 91 Express Lanes & SR-91 & Dec 1995 & $\begin{array}{l}\text { New } \\
\text { construction }\end{array}$ & 10 & 4 & No & Plastic posts \\
\hline San Diego & I-15 Express Lanes & $1-15$ & Dec 1996 & $\begin{array}{l}\text { Conversion/new } \\
\text { construction }\end{array}$ & 20 & 4 & Partial & Concrete wall \\
\hline Houston & Katy Freeway Managed Lanes & $1-10$ & Jan 1998 & $\begin{array}{l}\text { Conversion/new } \\
\text { construction }\end{array}$ & 12 & 4 & No & Plastic posts \\
\hline Houston & Northwest Highway QuickRide & US-290 & Dec 2000 & Conversion & 15 & 1 & Yes & Concrete wall \\
\hline Minneapolis & I-394 MnPASS Express Lanes ${ }^{\text {b }}$ & $1-394$ & May 2005 & Conversion & 8 & 2 & Partial & $\begin{array}{l}\text { Painted lines/ } \\
\text { concrete wall }\end{array}$ \\
\hline Salt Lake City & I-15 Express Lanes & $1-15$ & Sept 2006 & Conversion & 40 & 2 & No & Painted lines \\
\hline Denver & 1-25 Express Lanes & $1-25$ & June 2006 & Conversion & 7 & 2 & Yes & Concrete wall \\
\hline Seattle & SR-167 HOT Lanes ${ }^{c}$ & SR-167 & May 2008 & Conversion & 12 & 2 & No & Painted lines \\
\hline Miami & 95 Express & $1-95$ & Dec 2008 & $\begin{array}{l}\text { Conversion/new } \\
\text { construction }\end{array}$ & 7 & 4 & No & Plastic posts \\
\hline Minneapolis & I-35W MnPASS Express Lanes ${ }^{c}$ & $\mathrm{l}-35 \mathrm{~W}$ & Sept 2009 & Conversion & 16 & 2 & No & Painted line \\
\hline Bay Area & I-680 Sunol Express Lanes ${ }^{d}$ & $1-680$ & Sept 2010 & Conversion & 14 & 1 & No & Painted lines \\
\hline Atlanta & 1-85 Express Lanes & $1-85$ & Sept 2011 & Conversion & 16 & 2 & No & Painted lines \\
\hline
\end{tabular}

a This date refers to the first opening of the HOT lane while the remaining columns refer to current conditions. In some cases, particularly San Diego (1-15) and Houston (1-10), the facilities have been expanded so that current conditions do not reflect those when the lane opened.

${ }^{b}$ Minneapolis (1-394) is composed of two segments. The western segment from I-494 to SH-100 consists of a single dedicated lane in each direction painted line separated from the general purpose lanes. The eastern segment from SH-100 to I-94 consists of two reversible lanes concrete barrier separated from the general purpose lanes.

${ }^{c}$ HOT lane is longer in the northbound direction than the southbound direction. The longer length is presented here and used for subsequent calculations.

${ }^{d}$ This lane currently operates only in the southbound direction. Subsequent calculations, such as bus ridership, consider flows only in one direction.

HOT lane origin affects transit. HOT lanes may be newly-constructed, converted from an existing high-occupancy vehicle (HOV) lane, or a combination of both. New construction adds managed road capacity, whereas conversion adds managed road access for low-occupancy vehicles willing to pay the toll.

Capacity expansion (building new HOT lanes) is thought to generally benefit transit as the new and managed infrastructure speeds transit travel and improves reliability. For example, Miami's I-95 project, which combined new construction with conversion, reduced bus travel times along the corridor by 68 percent (Pessaro and Van Nostrand 2011). These benefits are thought to grow if the new lanes link previously-unconnected portions of a regional HOV network (Poole and Orski 2003; Barker and Polzin 2004; Buxbaum et al. 2010), as is the vision in the San Francisco Bay Area (Metropolitan Transportation Commission 2007). In a worst case scenario, new HOT lane capacity is unlikely to degrade existing conditions for transit. 
By contrast, access expansion (opening HOV lanes to paying motorists) without capacity expansion raises the specter of new low-occupancy vehicles worsening the traffic conditions for buses in the managed lane (Turnbull 2008; Perez, Giordano, and Stamm 2011). This outcome is seen as particularly inequitable for existing transit users (Lari and Buckeye 1999; Weinstein and Sciara 2006) and appears to be happening along Salt Lake City's I-15, where lane underpricing (due to legal restraints on toll levels) and poor lane enforcement have resulted in new peak-period congestion in the converted HOT lane.

To ward off such negative possibilities, HOT lanes can prioritize their operations to place transit at the top of a hierarchy of users (Swisher et al. 2003). For example, an agreement between Denver's I-25 HOT lane and the local transit agency specifies that any degradation in bus travel times triggers a policy review and may lead to consideration of a toll increase (State of Colorado and Regional Transportation District 2011). Consequently, monthly progress reports list the number of buses that exceed the allotted lane travel time (HPTE 2010). This process has produced positive results. For example, Turnbull (2008) reports that Denver's HOT lane management acted quickly when it discovered that the additional vehicles on the newly-converted HOT lane were overwhelming the clearing capacity of a pre-existing traffic signal at the lane's exit ramp and causing some upstream delay. The agency had the signal timing adjusted to account for the now higher vehicle flows debouching from the HOT lane. Legislating such monitoring programs to avoid service degradation is seen as critical for ensuring public confidence with HOV to HOT conversions (Perez, Giordano, and Stamm 2011; Parsons Brinckerhoff 2011). Besides Salt Lake City, such monitoring programs seem to be working. A federal review found that "generally, HOT lane conversions have achieved their goals of gaining better use of underutilized HOV lanes and maintaining congestion-free travel for toll paying users without subjecting HOV and transit users to lower service levels" (K.T. Analytics and Cambridge Systematics 2008). In fact, many argue that converting HOV lanes to HOT lanes and raising occupancy thresholds is the only way to maintain levels-of-service into the future as the number of qualifying carpools grow (Poole and Orski 1999; Metropolitan Transportation Commission 2007; Swisher et al. 2003; Meyer et al. 2006).

\section{Configuration}

Table 1 also describes the configuration of the HOT lanes. Currently, the typical HOT lane has a median length of 13 miles, serves a downtown area, and sees strong inbound flows in the morning and outbound flows in the afternoon. Salt Lake City's I-15 is an outlier at 40 miles in length (and under expansion to 60). This lane connects the many communities of the Wasatch Front and reports less-pronounced directional flows. The HOT lanes in Seattle, the Bay Area, and Orange County also vary slightly, as they serve commuting flows to secondary centers, not their respective region's primary downtown.

HOT lane facilities range between one and four lanes. Two facilities currently consist of only a single lane-Houston's US-290 is a reversible lane, and the Bay Area's 1-680 runs only southbound-but both are slated for expansion. Six facilities consist of two lanes. These are typically a single lane in each direction; however, Denver's I-25 and the eastern portion of Minneapolis's 1-394 are reversible double lanes, which switch direction to accommodate peak traffic flow. The remaining four facilities consist of two lanes in each 
direction. San Diego's I-15 has a movable barrier between those lanes to toggle between a 2/2 and a 3/1 lane configuration. Single and fully-reversible lanes can present a problem for transit service, as reverse-commute and deadheading buses cannot follow the same return path. The need to operate an alternative route may be a source of confusion for passengers, and the potential to face additional traffic may both slow cycle times (thus requiring more buses to provide the same capacity) and reduce the agency's ability to serve growing reverse-commute markets. There appears to be a trend to replace fully-reversible facilities with lanes operating continuously in both directions based on recent and planned projects in Houston and San Diego.

HOT lanes are separated from the adjacent unmanaged general-purpose lanes and have limited access points. Separation treatments range in cost, permanence, and permeability from a simple painted line to concrete walls (Jersey barriers). A middle ground that has been favored in several implementations is a barrier made of breakaway plastic posts (candlestick pylons), which deter illegal entry into the lanes but still allow for access in emergency situations (for more discussion on barriers see Hlavacek, Vitek, and Machemehl 2007, or Davis 2011).

Transit operators report improved travel conditions once inside converted HOT lanes, as the limited access increases the predictability of traffic and prevents the random and disruptive merging endemic to open-access HOV lanes (Munnich and Buckeye 2007). At the same time, transit operators report increased difficulty in specific locations of entering the converted HOT lanes now that access is limited. For example, many bus drivers along Seattle's SR-167 forgo using the HOT lane, as quickly crossing from the right-side highway entrance ramp to the left-side HOT lane entry is a difficult maneuver. Similarly, bus drivers along Minneapolis's 1-394 found entry difficult at one particular access point and complained that motorists, who were now enjoying the smoother flows of the limited-entry HOT lane, were less likely to yield to buses at the access points (Cambridge Systematics 2006). Transit agencies need to be involved in HOT lane planning to avoid conflicts with bus routes (Loudon, Synn, and Miller 2010). One configuration solution to access problems, implemented in Houston and San Diego, is to construct direct-access ramps to the HOT lanes. Another solution is to expand the access areas. Minneapolis's 1-35W, for example, is designed to be largely open access and systems elsewhere are considering such policies.

\section{Transit Integration with HOT Lanes}

\section{Bus Service Provision}

Table 2 shows that every HOT lane has bus service, which suggests that transit is not only compatible, but also complementary. Transit is seen as central to achieving the person-throughput objectives of HOT lanes as demand grows over time. Consequently, the development of a HOT lane often provides a unique opportunity to increase transit supply in a corridor. Miami, which had repeatedly failed to gain voter approval for increasing local transit funding, was able to use federal monies for the HOT lane project to purchase buses to operate three new express routes (Florida Department of Transportation 2012). Federal funding was similarly leveraged in Minneapolis (Buckeye 2011) and Atlanta (Vu 2011). In San Diego, the HOT lane project was designed, in part, to fund new express bus service along the corridor (Supernak 2005). 


\section{TABLE 2.}

Bus Service on HOT Lanes

\begin{tabular}{|c|c|c|c|c|c|c|c|c|}
\hline \multirow[b]{2}{*}{ Region } & \multirow[b]{2}{*}{ Corridor } & \multirow[b]{2}{*}{ Operators } & \multicolumn{3}{|c|}{ Weekday Bus } & \multicolumn{2}{|c|}{ Fares } & \multirow[b]{2}{*}{ Bus Route Numbers } \\
\hline & & & Routes & Trips & $\begin{array}{l}\text { Trips / } \\
\text { Routes }\end{array}$ & Highest & Lowest & \\
\hline Orange Co. & SR-91 & 2 & 2 & 39 & 20 & 4.50 & 3.00 & $\underline{216}, 794$ \\
\hline San Diego & $1-15$ & 1 & 6 & 141 & 24 & 5.00 & 2.50 & $\underline{20}, 810,820,850,860,880$ \\
\hline Houston & $1-10$ & 1 & 6 & 391 & 65 & 4.50 & 1.25 & 131 221, 222, 228 (\$3.75), 229 (\$3.75), 298 \\
\hline Houston & US-290 & 1 & 4 & 236 & 59 & 4.50 & 3.25 & $214(\$ 3.75), 216,217,219$ \\
\hline Minneapolis & $1-394$ & 4 & 38 & 548 & 14 & 3.00 & 1.75 & $\begin{array}{l}490,587,589,643,649,652,663,664,665,667,668,670, \\
671,672,673,674,675,677,679,680,690,691,692,697, \\
698,699,742,747,756,758,764,772,774,776,777,790, \\
793,795\end{array}$ \\
\hline Salt Lake City & $1-15$ & 1 & 12 & 76 & 6 & 5.00 & 5.00 & $471,472,473,801,802,803,804,805,806,807,808,810$ \\
\hline Denver & $1-25$ & 1 & 12 & 434 & 36 & 5.00 & 4.00 & $\begin{array}{l}\frac{B V}{122 X}, B X / B M X, L, H X, T, 31 X, 40 X, 80 X, 86 X, \underline{120 X} \\
\text {, }\end{array}$ \\
\hline Seattle & SR-167 & 2 & 2 & 88 & 44 & 4.00 & 2.50 & 566,952 \\
\hline Miami & $1-95$ & 2 & 4 & 259 & 65 & 2.35 & 2.35 & $\begin{array}{l}95 \text { Golden Glades, } 95 \text { Dade-Broward Express, I-95 } \\
\text { Express Miramar, I-95 Express Pembroke Pines }\end{array}$ \\
\hline Minneapolis & $\mathrm{I}-35 \mathrm{~W}$ & 4 & 26 & 495 & 19 & 3.00 & 1.75 & $\begin{array}{l}146,156,440,460,464,465,467,470,472,475,476,477, \\
478,479,491,492,535,552,553,554,558,578,579,597, \\
684,695\end{array}$ \\
\hline Bay Area & $1-680$ & 1 & 1 & 30 & 30 & 4.00 & 4.00 & 180 \\
\hline Atlanta & $1-85$ & 2 & 8 & 133 & 17 & 4.00 & 3.00 & $101,102,103,410,411,412,413,416$ \\
\hline
\end{tabular}

Note: Information current for January 2012. In the Bus Route Number column, bolded routes charge the lower fares, underlined routes have weekend service, and italicized routes charge local fares. Houston has multiple fare levels which are noted in (parentheses) for routes that do not charge the highest or lowest fare.

HOT lanes generally offer express, weekday bus services often only in the peak-flow direction. This express orientation is not surprising since longer bus routes without intermediate stops benefit the most from the reliable travel times offered by HOT lanes. Furthermore, HOT lanes typically funnel traffic to dense employment centers, which favors express, weekday operations. Table 2 shows that of the 121 bus routes identified that use HOT lanes, only 4 charge local fares and only 6 run on weekends.

The longer-distance nature of HOT lane bus service increases the likelihood of routes crossing jurisdictional boundaries and, consequently, of multiple transit operators using the same HOT lane. Multiple operators serve HOT lanes in 4 of the 10 regions studied, typically when a bus route starts in a different county from the HOT lane, such as a Riverside County bus using Orange County's SR-91. This situation increases the challenge of coordinating information for users. Miami's I-95 website, for example, very elegantly presents unified information on all bus routes using the facility even though two transit agencies provide those services. This presentation is exceptional. No other HOT lane website includes a map of transit service available on the facility. Among transit agencies, only Minneapolis's MetroTransit provides unified information on routes from different operators using the HOT lanes. 
The express nature of HOT lane bus service commands high and variable fares. Nine HOT lanes serve bus routes that charge between $\$ 4$ and $\$ 5$ per trip, much higher than standard fares. Furthermore, HOT lane bus service typically has two pricing tiers, which reflect distinctions in the distance traveled (Atlanta has two distance rates), the quality of service (San Diego offers "express" and "premium express" service with more comfortable buses and fewer stops), or the operating agency (Riverside Transit Agency and the Orange County Transportation Authority charge different express rates along the same corridor). Houston's HOT lane bus service has even more fare variation, with three distanced-based express-bus pricing tiers as well as one local rate. Table 2 shows that the vast majority of routes charge the higher fare.

Transit agencies have adopted two general strategies to bus provision on HOT lanes. The first and more popular approach provides lower-coverage, higher-frequency line-haul service and typically collects passengers already assembled at park-and-ride lots and transit centers. The second approach provides higher-coverage, lower-frequency feeder plus linehaul service and collects passengers from neighborhoods as well. Figure 2 presents the number of bus routes on each HOT lane and the ratio of daily trips per route. Houston, Miami, and Seattle exemplify the first strategy, with few routes but many trips per route. Minneapolis and Salt Lake City exemplify the second strategy, with many routes but fewer trips per route. Denver presents a third option, with a high number of routes and high frequencies per route.

FIGURE 2.

Transit service on HOT lanes

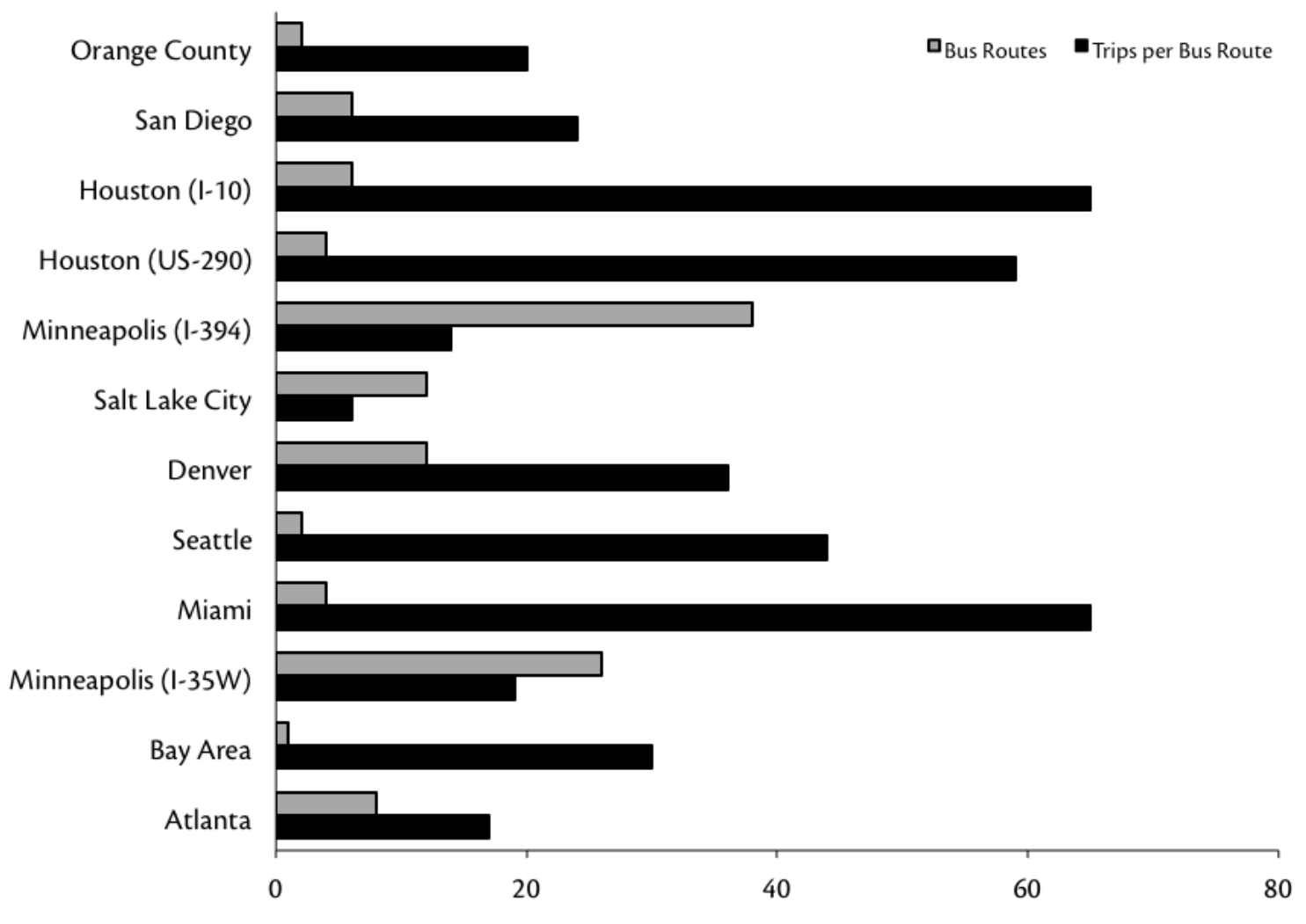




\section{Park-and-Ride Provision}

Bus provision on all HOT lanes is supported by park-and-ride lots either upstream or along the managed lanes themselves. While general park-and-ride design principles, such as maximizing upstream flows and managing bus headways (Neudorff et al. 2011), continue to hold, HOT lanes offer some unique possibilities.

First, the development of a HOT lane often provides substantial funding to increase parkand-ride provision. For example, Atlanta's I-85 HOT lane conversion was part of a $\$ 182$ million regional congestion reduction project that allocated $\$ 80$ million for park-and-ride capacity expansion at 11 sites around the region (roughly twice the $\$ 42$ million spent on new over-the-road coaches). Two new park-and-ride lots were built and one park-andride lot was expanded to serve the HOT lane specifically (Georgia State Road and Tollway Authority 2010). These three sites combined added roughly 2,200 new parking spots ( $\mathrm{Vu}$ 2011).

Second, because HOT lanes have limited entry points, the physical connection between these lanes and the park-and-ride lot takes on added importance. Many lots are sited well upstream of the HOT lane entrance and need no special accommodations. For example, the HOT lane expansion on Houston's I-10 included the construction of the new 2,377 spot Kingsland Park-and-Ride lot eight miles upstream from the HOT lane's entrance. Buses leaving the Kingsland lot enter the HOT lane downstream like any other vehicle. However, lots located along the lane may require difficult movements for buses to enter the highway and then cross all the general-purpose lanes to enter the HOT lane. The Houston I-10 expansion also included the construction of the new 2,428 spot Addicks Park-and-Ride lot just downstream from the lane's entrance. Buses leaving this lot use a special bridge to pass over the general-purpose lanes and have a direct-access ramp down to the HOT lane. Such direct-access ramps, as noted earlier, minimize traffic conflicts and maximize the speed at which an express bus can pass between the HOT lane and an offline park-and-ride lot.

Just as not all park-and-ride lots serving a HOT lane are located along that lane, not all park-and-ride lots located along a HOT lane serve bus routes traveling on that lane. Many lots are designed exclusively for carpooling and vanpooling or serve a perpendicular transit line that does not use the HOT lane. Table 3 presents comparative statistics for all the park-and-ride lots that are both located within one mile of a HOT lane and have bus service that actually uses those HOT lanes. By this definition, three quarters of HOT lanes have at least one park-and-ride lot along their corridor. Of these facilities, the median number of lots is five, with an average spacing of one lot every three miles. The median number of parking spaces in these lots is 1,845 , with a median ratio of 513 spaces per lot or 160 spaces per mile of HOT lane. 
TABLE 3.

Park and Ride Lots within a One-Mile Buffer of HOT Lanes

\begin{tabular}{|c|c|c|c|c|c|c|c|}
\hline \multirow[b]{2}{*}{ Region } & \multirow[b]{2}{*}{ Corridor } & \multicolumn{2}{|c|}{ Lots } & \multicolumn{3}{|c|}{ Spaces } & \multirow{2}{*}{$\begin{array}{l}\text { Lot Names and Number of Parking Spaces } \\
\text { (organized from furthest out to downtown, where applicable) }\end{array}$} \\
\hline & & Total & $\begin{array}{l}\text { Per } \\
\text { Mile }\end{array}$ & Total & $\begin{array}{l}\text { Per } \\
\text { Lot }\end{array}$ & $\begin{array}{l}\text { Per } \\
\text { Mile }\end{array}$ & \\
\hline Orange Co. & SR-91 & 0 & 0.000 & 0 & 0 & 0 & - \\
\hline San Diego & $1-15$ & 12 & 0.600 & 1,845 & 154 & 92 & $\begin{array}{l}\text { Escondido Transit Center (580); Felicita Ave (30); Del Lago Transit } \\
\text { Station (160); Rancho Bernardo Rd (15); Rancho Bernardo Transit } \\
\text { Station (190); Rancho Carmel Dr (125); SR56 (70); Sabre Springs / } \\
\text { Peñasquitos Transit Station (250); Stoney Creek Rd (132); Paseo } \\
\text { Cardiel (88); Freeport Rd (102); Poway Rd (103); }\end{array}$ \\
\hline Houston & $1-10$ & 2 & 0.167 & 2,623 & 1,312 & 219 & Addicks P\&R (2,428); Northwest Transit Center (195) \\
\hline Houston & US-290 & 4 & 0.800 & 4,596 & 1,149 & 306 & $\begin{array}{l}\text { Northwest Station (2,361); W. Little York (1,102); Pinemont (938); } \\
\text { Northwest Transit Center (195) }\end{array}$ \\
\hline Minneapolis & $1-394$ & 5 & 0.625 & 1,351 & 270 & 169 & $\begin{array}{l}\text { Plymouth Road Transit Center (111); CR } 73 \text { (732); General Mills } \\
\text { Boulevard (123); Louisiana Ave Transit Center (330); Park Place (55) }\end{array}$ \\
\hline Salt Lake City & $1-15$ & 5 & 0.125 & 1,459 & 292 & 37 & $\begin{array}{l}\text { 160N 600W, Kaysville (231); Layton Hills Mall (379); Thanksgiving Point } \\
\text { Station (422); } 100 \text { E. Main St, American Fork (227) American Fork } \\
\text { Station (200) }\end{array}$ \\
\hline Denver & $1-25$ & 0 & 0.000 & 0 & 0 & 0 & - \\
\hline Seattle & SR-167 & 5 & 0.417 & 1,985 & 662 & 165 & Auburn Station (631); Auburn P\&R (358); Kent Station (996); \\
\hline Miami & $1-95$ & 0 & 0.000 & 0 & 0 & 0 & - \\
\hline Minneapolis & $\mathrm{I}-35 \mathrm{~W}$ & 5 & 0.313 & 2,566 & 513 & 160 & $\begin{array}{l}\text { Heart of the City (370); Burnsville Transit Station (1,376); St. Luke's (100); } \\
\text { South Bloomington Transit Center (195); Knox Ave }(525)\end{array}$ \\
\hline Bay Area & $1-680$ & 1 & 0.071 & 127 & 127 & 9 & Mission Boulevard (127) \\
\hline Atlanta & $1-85$ & 2 & 0.125 & 1,060 & 530 & 66 & Discover Mills (554); Indian Trail (506) \\
\hline
\end{tabular}

Note: Only those lots that are served by bus routes that use the HOT lanes are considered here. Bolded lots have direct access ramps to the HOT lanes.

\section{Transit Ridership}

The purpose of bus and park-and-ride provision is to encourage transit ridership. The most recent comparative information on weekday ridership, shown in Table 4, demonstrates that transit can attract riders in HOT lane corridors. On a typical weekday, the 12 HOT lanes in the U.S. carry more than 67,000 bus passengers. The median weekday transit ridership per HOT lane is 3,882 riders; however, the 3 most transit-productive facilities, those in Denver and Minneapolis, each carry more than 11,000 bus passengers per weekday. The only HOT lanes that carry fewer than 2,000 bus passengers per weekday are those in Orange County and the Bay Area, where the HOT lane serves secondary centers with dispersed employment locations. 
TABLE 4.

Weekday Bus Trips and Ridership on HOT Lanes

\begin{tabular}{|c|c|c|c|c|c|}
\hline \multirow{2}{*}{ Region } & \multirow{2}{*}{ Corridor } & \multicolumn{4}{|c|}{ Weekday Bus } \\
\hline & & Trips $^{a}$ & Riders & Rider Count Period(s) & Riders/Trip \\
\hline Orange Co. & SR-91 & 39 & 450 & March 2010; Oct 2011 & 12 \\
\hline San Diego & $1-15$ & 141 & 2,158 & Spring 2011; Nov 2011 & 15 \\
\hline Houston & $1-10$ & 391 & 8,027 & Fiscal Year 2011 & 21 \\
\hline Houston & US-290 & 236 & 4,526 & Fiscal Year 2011 & 19 \\
\hline Minneapolis & $1-394$ & 548 & 12,141 & Calendar Year 2011 (est) & 22 \\
\hline Salt Lake City & $1-15$ & 76 & 3,477 & Calendar Year 2011 & 46 \\
\hline Denver ${ }^{b}$ & $1-25$ & 434 & 14,840 & Aug - Dec 2011 & 34 \\
\hline Seattle & SR-167 & 88 & 2,334 & Oct-Dec 2011;Dec 2011 & 27 \\
\hline Miami & $1-95$ & 259 & 4,286 & June 2011 & 17 \\
\hline Minneapolis & $\mathrm{I}-35 \mathrm{~W}$ & 495 & 11,647 & Calendar Year 2011 (est) & 24 \\
\hline Bay Area ${ }^{c}$ & $1-680$ & 30 & 307 & Calendar Year 2011 & 10 \\
\hline Atlanta & $1-85$ & 133 & 3,179 & Sept 12 - Oct 7, 2011 & 24 \\
\hline
\end{tabular}

a Trips based on January 2012 schedules.

${ }^{b}$ The $B, L$, and $120 X$ routes also operate some service in the reverse commute direction. This service does not use the HOT lanes, but the data on those trips and ridership are included in these totals.

' Since the Bay Area (1-680) HOT Lane is southbound only, only buses running in that direction and their ridership are counted.

The bus service on HOT lanes is relatively efficient with an average load factor of 23 passengers per bus trip. Salt Lake City's $1-15$ reports a particularly high load factor of double the national average due to the combination of strong demand for the limited peak-period service and the large seating capacity of the over-the-road coaches. The unfavorable land use conditions for transit along the HOT lanes in Orange County and the Bay Area result in the lowest load factors of 12 and 10, respectively.

A common concern of HOT lane development, particularly for HOV to HOT conversions, is that people who formerly rode transit to enjoy the managed-lane benefit will make a socially-undesirable mode shift to driving alone once they can purchase access to the same managed-lane benefit. Some HOT lane policies are expressly designed to limit this possibility. For example, the peak-period tolls on Denver's $1-25$ are legally bound to be at or above the express bus fare along the corridor (State of Colorado and Regional Transportation District 2011) so that driving never has an out-of-pocket cost advantage.

It is difficult to address this concern knowledgeably, as there has been limited research into such behavioral changes. An April 1998 examination of paying users of Houston's I-10 HOT lane, during a period when two-occupant vehicles could purchase peak-direction access otherwise restricted to three-occupant vehicles, found that 10.6 percent of the morning users and 5.3 percent of the afternoon users had previously taken the bus (Burris and Stockton 2004). A stated preference study of bus passengers on Houston's HOT lanes was conducted in 2003 to predict the modal impacts of allowing single-occupant vehicles to purchase access to the lanes. That study predicted that even with extended HOT lane hours and the maximum time savings at the lowest toll tested, fewer than 6.1 percent of current bus riders would shift to driving alone (Chum and Burris 2008). Evaluations of Orange County's SR-91 found that transit passengers did not shift to driving with the addition of the HOT lane (Sullivan 2002, 2000). These three studies hint at only small shifts from transit to driving, 
but do not provide particularly conclusive evidence. The first study was of a very small sample of early adopters to a very limited service, the second study was based on beliefs about future actions, and the third study considered the only HOT lane that had not been an HOV facility (and, therefore, did not previously afford transit any advantage).

Since a small amount of former transit users switching to driving with the introduction of a HOT lane may be compensated for by new riders, it is important to consider the net ridership impacts along the corridor. Here, the trends are not clear-cut, and a recent federal review could only characterize the effect as "mixed" (GAO 2012). Available studies report neutral impacts along Orange County's SR-91 (Sullivan 2002, 2000) and Denver's I-25 (Chum and Burris 2008) and positive impacts along Minneapolis's I-394 (13\% increase) (Chum and Burris 2008), Minneapolis's I-35W (18\% increase) (Buckeye 2011), Seattle's SR-167 (8\% increase) (Parsons Brinckerhoff 2011), and Miami's I-95 (57\% increase) (Pessaro and Van Nostrand 2011). No study reports negative impacts. These findings suggest that while the introduction of a HOT lane is unlikely to reduce ridership, it does not guarantee its growth. Unfortunately, many of these studies only look at growth on the bus lines on the HOT lane itself without necessarily considering the losses from parallel transit services.

The source of the "new" transit riders is critical. Ideally, these riders would be former drivers and thus represent a shift towards greater sustainability. In practice, many new riders of buses on HOT lanes come from other transit modes and, therefore, do not represent growth in system ridership. For example, a survey of the new riders on Miami's 95 Express Bus service found that 45 percent came from transit and a third of those from commuter rail (Pessaro and Van Nostrand 2011). This latter example demonstrates that the combination of bus and HOT lane may serve as a reasonable commuter rail alternative. Former rail patrons in Miami can leave from the same park-and-ride lot, but they arrive at their destination by a well-appointed, over-the-road bus without needing to transfer. However, this example also demonstrates the danger of counting only passengers along the HOT lane itself rather than considering competing transit routes. Since the ability to choose between long-haul transit modes is relatively common (e.g., bus routes on HOT lanes in Orange County, Seattle, Salt Lake City, and the Bay Area also have collocated stations along parallel commuter rail lines), reporting needs to be careful to net out losses on competing transit services when measuring bus gains on HOT lanes.

Finally, the development of HOT lanes presents a very important opportunity to market existing or new transit services to the general public. Because HOT lanes do represent a novelty, they are often featured on news stories. The annual report of Miami's I-95 HOT lanes counts the number of media mentions as "helping in providing the public valuable information on 95 Express goals and operations" (Florida Department of Transportation 2012). Publicity is seen as contributing to the success of the project, as 53 percent of new riders said the opening of the new HOT lanes influenced their decision to use transit. Similarly, public pressure has caused HOT lane marketing campaigns to promote transit in Denver (Ungemah, Swisher, and Tighe 2005) and Minneapolis (Munnich and Buckeye 2007).

\section{HOT Lane Revenues and Transit Subsidies}

An appealing feature of HOT lanes is that they earn revenues, which, in theory, could be used to subsidize transit. This section explores whether supportive legal structures are 
in place, whether toll revenues are available, and whether available revenues are actually transferred to subsidize transit.

\section{Legal Structures for Revenue Transfer}

Table 5 shows that most HOT lanes can legally transfer toll revenues to support transit along the corridor. Typically, the transferable funds are described as "excess" or "net" revenues and refer to monies earned after expenses. This approach raises the question of what constitutes an expense. Most systems only include operating expenses; however, some, such as Minneapolis's 1-394, also include capital expenses. Including more expenses reduces the availability of excess revenues for transit. An alternate approach, taken by Miami's I-95, is to define HOT lane expenses to include the transit subsidy. There, express bus service is seen as essential to the operation of the HOT lane and the two bus providers are guaranteed subsidy payments regardless of net revenues.

\section{TABLE 5.}

HOT Lane Operator and Legislated Revenue Transfer to Transit

\begin{tabular}{|c|c|c|c|}
\hline Region & Corridor & Operator & Legislated Revenue Transfer to Transit \\
\hline Orange Co. & SR-91 & Transit Agency & [No transfer despite transit agency owning facility] \\
\hline San Diego & $1-15$ & MPO & $\begin{array}{l}\text { "All remaining revenue shall be used in the } 1-15 \text { corridor exclusively for }(A) \text { the improvement } \\
\text { of transit service, including, but not limited to, support for transit operations, and (B) high- } \\
\text { occupancy vehicle facilities and shall not be used for any other purpose." }\end{array}$ \\
\hline Houston & $1-10$ & Toll Authority & [No transfer] \\
\hline Houston & US-290 & Transit Agency & [Excess revenues goes into transit general fund as transit agency owns the facility] \\
\hline Minneapolis & $1-394$ & State DOT & $\begin{array}{l}\text { "The commissioner shall spend remaining money in the account as follows: ... one-half must be } \\
\text { transferred to the Metropolitan Council for expansion and improvement of bus transit services } \\
\text { within the corridor beyond the level of service provided on the date of implementation." }\end{array}$ \\
\hline Salt Lake City & $1-15$ & State DOT & [No transfer] \\
\hline Denver & $1-25$ & State DOT & $\begin{array}{l}\text { "Excess revenues may then be used for transit purposes in the corridor. ... The parties wish to } \\
\text { clarify their intent that (1) the corridors to be benefitted by the Facility and (2) the corridors } \\
\text { where excess revenue may be expended include US } 36 \text { and North I-25 and may extend beyond } \\
\text { the boundaries [of] the Facility." }\end{array}$ \\
\hline Seattle & SR-167 & State DOT & [No transfer] \\
\hline Miami & $1-95$ & State DOT & $\begin{array}{l}\text { "All tolls so collected shall first be used to pay the annual cost of the operation [which includes } \\
\text { peak-period express bus service], maintenance, and improvement of the high-occupancy toll } \\
\text { lanes or express lanes project or associated transportation system. Any remaining toll revenue } \\
\text { from the high-occupancy toll lanes or express lanes shall be used by the department for the } \\
\text { construction, maintenance, or improvement of any road on the State Highway System within the } \\
\text { county or counties in which the toll revenues were collected or to support express bus service on } \\
\text { the facility where the toll revenues were collected." }\end{array}$ \\
\hline Minneapolis & $\mathrm{I}-35 \mathrm{~W}$ & State DOT & $\begin{array}{l}\text { "The commissioner shall ... allocate any remaining amount as follows: ... } 75 \text { percent to the } \\
\text { Metropolitan Council for improvement of bus transit services within the corridor including } \\
\text { transit capital expenses." }\end{array}$ \\
\hline Bay Area & $1-680$ & CCMA & $\begin{array}{l}\text { "All net revenue generate by the program ... shall be allocated pursuant to an expenditure plan } \\
\text { adopted biennially by the administering agency for transportation purposes within the program } \\
\text { area. The expenditure plan may include funding for the following: ... (B) Transit capital and } \\
\text { operations that directly serve the authorized corridors." }\end{array}$ \\
\hline Atlanta & $1-85$ & Toll Authority & [No transfer] \\
\hline
\end{tabular}


The legal structures also distinguish between allowing revenue transfers and requiring them. Denver's 1-25, Miami's 1-95, and the Bay Area's 1-680 all allow transfers of excess revenues for transit purposes but, to date, have chosen not to expend them on transit. (Excess revenues in Denver are being held in escrow to eventually help fund a tributary HOT lane and BRT service, and Miami is already subsidizing transit as part of its expense structure.) San Diego's I-15 and the two Minneapolis HOT lanes are required to transfer specified portions of their net revenues. San Diego must transfer its entire surplus to support transit, while Minneapolis must transfer three-quarters of net revenues along I-35W and half of net revenues along $1-394$.

There is some variety in the transit services that can be subsidized. Most systems require the subsidized transit be geographically located within the tolled corridor. Denver has amended its agreement to clarify that the monies from $1-25$ can be used on a tributary corridor beyond the tolled facility (Colorado Department of Transportation and Regional Transportation District 2011). Several regions specify that subsidies must support transit improvements and expansions. Minneapolis's 1-394 agreement is explicit that this refers to "bus transit services within the corridor beyond the level of service provided on the date of implementation" (State of Minnesota 2012). Other HOT lane agreements, such as those in Denver and the Bay Area, suggest that toll revenues can be used to subsidize existing services. No HOT lane limits transit subsidies to either operating or capital expenses; however, two facilities felt the need to make this explicit. Orange County's SR-91 legislation calls out operational expenses as acceptable while Minneapolis's I-394 legislation does the same for capital expenses.

A final case is when the transit agency operates the HOT lane. A logical assumption is that excess revenues would come back to the agency's general fund, which is the case with Houston's US-290; however, this arrangement is not consistent. Orange County's SR-91, which is also operated by a transit agency, is not allowed to divert any excess revenues from corridor highway improvements and the agency is, therefore, looking to double the length of the HOT lanes.

\section{HOT Lane Revenues and Expenses}

A supportive legal framework is only useful if there are toll revenues available for transferring. Loudon et al. (2010) delicately note that "the expectations for revenue generation by decision makers and the public are often inflated." Table 6 presents the reported revenues for fiscal year 2011, which vary widely from $\$ 25,467$ on Houston's $1-290$, which tolls for only an hour and a quarter in one direction on weekday mornings, to $\$ 41,245,590$ on Orange County's SR-91, which tolls all day in both directions every day of the week. The latter HOT lane had such a profit potential that it was initially built and owned by a private company. The median HOT lane revenue in fiscal year 2011 was a modest $\$ 2.6$ million. 
TABLE 6.

Revenues and Transit Subsidies of HOT Lanes

(Fiscal Year 2011)

\begin{tabular}{|c|c|c|c|c|c|c|}
\hline \multirow{2}{*}{ Region } & \multirow{2}{*}{ Corridor } & \multicolumn{3}{|c|}{ Operating } & \multicolumn{2}{|c|}{ Subsidy } \\
\hline & & Income & Expenses & Margin & Net & Per Profit \\
\hline Orange County & SR-91 & $\$ 41,245,590$ & $\$ 22,381,682$ & $46 \%$ & 0 & $0 \%$ \\
\hline San Diego & $\mid-15$ & $\$ 4,015,371$ & $\$ 2,456,865$ & $39 \%$ & $\$ 1,000,000$ & $64 \%$ \\
\hline Houston & $\mid-10$ & $\$ 6,715,041$ & $\$ 2,873,430$ & $57 \%$ & 0 & $0 \%$ \\
\hline Houston & US-290 & $\$ 25,467$ & $\$ 30,000$ & $-18 \%$ & 0 & $0 \%$ \\
\hline Minneapolis $^{\mathrm{a}}$ & $1-394$ & - & - & - & - & - \\
\hline Salt Lake City & $1-15$ & $\$ 439,474$ & $\$ 711,896$ & $-62 \%$ & 0 & $0 \%$ \\
\hline Denver & $1-25$ & $\$ 2,553,591$ & $\$ 2,003,131$ & $22 \%$ & 0 & $0 \%$ \\
\hline Seattle & SR-167 & $\$ 750,446$ & $\$ 1,092,346$ & $-46 \%$ & 0 & $0 \%$ \\
\hline Miami & $1-95$ & $\$ 15,085,957$ & $\$ 7,560,000^{b}$ & $50 \%$ & $\$ 2,610,185$ & $35 \%$ \\
\hline Minneapolis ${ }^{\mathrm{a}}$ & $\mathrm{I}-35 \mathrm{~W}$ & $\$ 2,640,684$ & $\$ 2,509,593$ & $5 \%$ & $\$ 179,000$ & $137 \%$ \\
\hline Bay Area $^{c}$ & $1-680$ & $\$ 628,961$ & $\$ 670,449$ & $-7 \%$ & 0 & $0 \%$ \\
\hline
\end{tabular}

a The income and expenses in Minneapolis are calculated jointly; however, subsidies are currently generated and allocated only along the I-35W corridor where the capital costs were fully paid for. This accounting arrangement results in a transit subsidy that appears to exceed the net revenues. It is expected that in 2014 the capital costs of I-394 will be paid off and I-394 will generate net revenues similar to those currently generated on $1-35 W$ to be used as subsidies.

${ }^{b}$ Estimated by HOT lane operator.

'The Bay Area's 1-680 HOT lanes opened in September 2010 and had just over nine month of operation in FY 2011. Atlanta's I-85 HOT lanes were not open during FY 2011 and are excluded from this table.

Table 6 also compares revenues to expenses to show that only six HOT lanes reported a surplus in 2011. The four facilities where capacity has been added through new construction are doing particularly well, with a median profit margin of 48 percent and a combined net revenue of $\$ 32$ million. Several of the currently unprofitable lanes are projected to generate a surplus in the near future. For example, Seattle's SR-167 reported revenues exceeding expenses in the last quarter of FY 2011 (Washington State Department of Transportation 2011) and Houston's US-290, which renegotiated its maintenance contract, showed a 31 percent profit margin for the 2012 fiscal year.

\section{Transit Subsidies}

The availability of excess toll revenues does not guarantee that they will be used to subsidize transit. Of the six HOT lanes reporting excess revenues, only three transferred portions of these monies to support bus service on the corridor. Miami spent $\$ 2.6$ million and San Diego spent $\$ 1.0$ million to fully subsidize express bus service along their respective HOT lanes. Minneapolis's I-35W spent $\$ 179,000$ to support transit. These transfers are perhaps less than the windfall that policy makers may imagine when instituting the policies; however, as King (2009) notes, these subsidies can be quite significant for funding service in the HOT lane corridor itself.

HOT lanes also may indirectly increase transit funding by assuming costs for HOV maintenance formerly borne by transit agencies. For example, Denver's I-25 and Houston's I-10 HOT lanes had previously been transit agency-operated HOV lanes. When these HOV lanes were converted to HOT lanes, toll authorities took over responsibility for operation and maintenance. These assumed costs can be substantial. For example, in FY 2011, Denver's I-25 spent $\$ 305,459$ for daily operation of the HOT lane, which includes reversing 
its direction and maintaining the gates, as well as an additional $\$ 381,648$ for contracted maintenance, which includes routine tasks such as sweeping, crack sealing, guard rail repair, etc., and seasonal responsibilities such as snow and ice removal. These savings can occur only if the transit agency can shed all the associated costs of operating the lane. In Houston, the transit agency redistributed the labor force previously working on the I-10 lane to provide support elsewhere in their HOV network and, therefore, did not realize savings from off-loading that HOV maintenance responsibility to the HOT lane operator.

\section{Conclusions}

HOT lanes represent a new opportunity for transit agencies with many potential benefits, including increased funding, faster travel speeds, more riders, and greater community visibility. However, these benefits do not emerge automatically. Transit agencies need to work closely with HOT lane developers to realize these positive externalities and avoid negative ones, such as access conflicts, increased traffic congestion, and ridership losses. This paper uses the experience at existing facilities to explain how HOT lanes impact transit. The purpose of this research is to establish the stakes involved with HOT lane development and to help transit agencies to take advantage of this new opportunity.

\section{Acknowledgment}

The author thanks Peter Fahrenwald, David Phillips, Kenneth Buckeye, John Allen, Linda Young, several members of the staff of the Chicago Metropolitan Agency for Planning (CMAP), and two anonymous reviewers for commenting on drafts. The author also thanks the transportation agency professionals in the 10 studied regions for sharing their time and data and the Regional Transportation Authority (RTA) in Chicago for supporting this research.

\section{References}

Barker, W. G., and S. E. Polzin. 2004. Synergies of bus rapid transit and high-occupancy toll lanes: Simulation of bus rapid transit in congested corridor with roadway value pricing. Transportation Research Record 1884: 3-9.

Buckeye, Kenneth R. 2011. Minnesota's Urban Partnership Agreement 2011 Update. FHWA Webinar December 15, Minneapolis, MN.

Burris, M. W., and B. R. Stockton. 2004. HOT lanes in Houston-Six years of experience. Journal of Public Transportation 7: 1-22.

Buxbaum, Jeffrey N., Matthew Click, Thomas Higgins, and Kiran Bhatt. 2010. Integrating pricing into the metropolitan transportation planning process: Four case studies. Final Report FHWA-HOP-11-002. Washington, DC: U.S. Department of Transportation.

Cambridge Systematics. 2006. I-394 MnPASS technical evaluation. Final Report. Minneapolis, MN: Minnesota Department of Transportation. 
Chum, G. L., and M. W. Burris. 2008. Potential mode shift from transit to single-occupancy vehicles on a high-occupancy toll lane. Transportation Research Record 2072: 10-19.

Colorado Department of Transportation, and Regional Transportation District. 2011. First amendment to intergovernmental agreement between the Colorado Tolling Enterprise, the Colorado Department of Transportation, and the Regional Transportation District Regarding the North I-25 and US 36 Expres Lanes Facility.

Davis, M. 2011. Current industry trends for separating express lanes from general purpose lanes. White Paper. Atkins, Ltd.

Fielding, G. J. 1995. Congestion pricing and the future of transit. Journal of Transport Geography 3(4): 239-246.

Fielding, G. J., and D. B. Klein. 1993. High occupancy/toll lanes: Phasing in congestion pricing a lane at a time. Policy Study No. 170. Reason Foundation.

Florida Department of Transportation. 2012. 95 Express annual report: Covering July 1, 2010 through June 30, 2011. Final Report. Miami: Florida Department of Transportation.

GAO. 2012. Traffic congestion: Road pricing can help reduce congestion, but equity concerns may grow. GAO-12-119. Washington, DC: Government Accountability Office.

Georgia State Road and Tollway Authority. 2010. Atlanta Congestion reduction demonstration grant: A 2:1 Investment in transit over highways. Georgia Department of Transportation.

Hardy, M. H. 2009. Transit response to congestion pricing opportunities: Policy and practice in the U.S. Journal of Public Transportation 12(3): 61-77.

Hlavacek, I., M. Vitek, and R. B. Machemehl. 2007. Best practices: Separation devices between toll lanes and free lanes. FHWA/TX-07/0-5426-1. Austin, TX: Texas Department of Transportation.

HPTE. 2010. I-25 Express lanes monthly progress report June 2010. Denver: Colorado Department of Transportation.

K. T. Analytics, and Cambridge Systematics. 2008. Value Pricing pilot program: Lessons learned. Final Report FHWA-HOP-08-023. Washington, DC: USDOT Federal Highway Administration.

King, D.A. 2009. Remediating inequity in transportation finance. Washington, DC: Transportation Research Board.

Lari, A. Z., and K. R. Buckeye. 1999. High occupancy toll lane system: A concept plan for the twin cities. Transportation Research Record 1659: 111-118.

Loudon, W. R., J. Synn, and H. Miller. 2010. Consideration of congestion pricing and managed lanes in metropolitan transportation planning. Transportation Research Record 2187: 60-67. 
Metropolitan Transportation Commission. 2007. Bay Area high occupancy toll (HOT) network study. Final Report. Oakland, CA: Metropolitan Transportation Commission.

Meyer, M. D., L. Saben, W. Shephard, and D. E. Drake. 2006. Feasibility assessment of metropolitan high-occupancy toll lane network in Atlanta, Georgia. Transportation Research Record 1959: 159-167.

Munnich, L. W., and K. R. Buckeye. 2007. I-394 MnPASS high-occupancy toll lanes: Planning and operational issues and outcomes (lessons learned in year 1). Transportation Research Record 1996: 49-57.

Neudorff, Louis G., Jeffrey E. Randall, Robert Reiss, and Robert Gordon. 2011. Managed lanes-Chapter 8. In Freeway Management and Operations Handbook, Revised, 1-77. Washington, DC: U.S. Department of Transportation.

Parsons Brinckerhoff. 2011. NCHRP Web-only document 174: Performance measurement and evaluation of tolling and congestion pricing projects. Washington, DC: Transportation Research Board.

Perez, Benjamin Gerry, Reno Giordano, and Heidi Stamm. 2011. NCHRP Report 694: Evaluation and performance measurement of congestion pricing projects. National Cooperative Highway Research Program. Washington, DC: Transportation Research Board.

Pessaro, Brian, and Caleb Van Nostrand. 2011. Miami Urban Partnership Agreement (UPA) Project: Phase 1 Transit evaluation report. Final Report FTA- FL- 26-7110.2011.1. Tampa, FL: National Bus Rapid Transit Institute.

Poole, R. W., and C. K. Orski. 1999. Building a case for HOT lanes. 257, Policy Study. Los Angeles, CA: Reason Public Policy Institute.

Poole, R. W., and C. K. Orski. 2003. HOT networks: A new plan for congestion relief and better transit. 305, Policy Study. Los Angeles, CA: Reason Public Policy Institute.

State of Colorado, and Regional Transportation District. 2011. Intergovernmental Agreement US 36 Managed Lane Project Segments 1 and 2: Exhibit D, Tolling and use policy.

State of Minnesota. 2012. Minnesota Statutes: User Fees; High Occupancy Vehicle and Dynamic Shoulder Lanes.

Sullivan, E. C. 2000. Continuation study to evaluate the impacts of the SR 91 value-priced express lanes. Final report. Sacramento: State of California Department of Transportation.

Sullivan, E. C. 2002. State Route 91 value-priced express lanes: Updated observations. Transportation Research Record 1812: 37-42.

Supernak, Janusz. 2005. HOT lanes on Interstate 15 in San Diego: Technology, impacts, and equity issues. Cancun, Mexico. 
Swisher, M., W. L. Eisele, D. Ungemah, and G. D. Goodin. 2003. Life-cycle graphical representation of managed high-occupancy vehicle lane evolution. Transportation Research Record 1856: 161-167.

Turnbull, K. F. 2008. High-occupancy toll lanes and public transportation. Transportation Research Record 2065: 36-40.

Ungemah, D., M. Swisher, and C. D. Tighe. 2005. Discussing high-occupancy toll lanes with the Denver, Colorado, public. Transportation Research Record 1932: 129-136.

Vu, Patrick. 2011. Atlanta's CRD update. FHWA Webinar December 15, Atlanta.

Washington State Department of Transportation. 2011. SR 167 HOT lanes pilot project: Third annual performance summary (May 2008-April 2011).

Weinstein, A., and G. C. Sciara. 2006. Unraveling equity in HOT lane planning: A view from practice. Journal of Planning Education and Research 26(2): 174-184.

\section{About the Author}

Gregory L. NeWmARK (gnewmark@cnt.org) is a senior research analyst at the Center for Neighborhood Technology, a research fellow at the Chaddick Institute for Metropolitan Development at DePaul University, and a lecturer at the Harris School of Public Policy Studies at the University of Chicago. 